\title{
Geloven in de stad van die mens
}

G Heitink*

(VU, Nederland)

\section{ABSTRACT}

\section{Belief and Faiths in the secular city}

More than thirty years after the publication of Harvey Cox well-known book, "The secular city", churches are still in doubt about the question how to deal with modernity. In this article the approach is chosen where the key words differentiation, secularization and individualization, connected with a plurality of belief systems are analyzed and connected with a plurality. Christianity encloses individual, social and public forms of faith and belief. Local churches and congregations can be defined as social forms of christianity. They have to be open for individual and public forms of religion to break up the isolated position and defensive attitude of the churches against modernity.

Ruim dertig jaar geleden verscheen het bekende boek van Harvey Cox, De stad van de mens ${ }^{1}$. Het hierin geschetste beeld van de moderne Amerikaanse samenleving is sindsdien ook elders in de wereld alleen maar herkenbaarder geworden. De globalisering zet door. Dat geldt niet alleen voor West-Europa, maar waarschijnlijk ook in toenemende mate voor de geurbaniseerde delen van Zuid Afrika. Moeilijker valt het vandaag Cox's optimistische theologische interpretatie van "the secular city" te delen. Het spreken over "de kerk als Gods avant-garde” bijvoorbeeld, staat tamelijk haaks op een proces van kerkverdamping en traditieverlies waarmee het moderniseringsproces in de Westerse wereld gepaard gaat.

Deze constatering dient echter vergezeld te gaan van de verplichting te zoeken naar nieuwe kansen voor geloof en kerk in een veelkleurige en veelvormige verstedelijkte samenleving. In deze woorden klinkt iets door van verwachting, een nieuw élan: $\mathrm{Er}$ is niet alleen misère, er liggen ook kansen en mogelijkheden. In de stad klopt het hart van de cultuur. Juist hier worden de kerken uitgedaagd zichzelf te vernieuwen. In dit artikel zoek ik vanuit het perspectief van de praktische theologie naar nieuwe wegen voor kerkelijke presentie in de stad van de mens. Ik doe dit aan de

*Honorêre Professor, Departement Praktiese Teologie, Universiteit van Pretoria. 
hand van enkele kernbegrippen, die ons door het moderniseringsproces worden aangereikt: differentiatie, secularisering, individualisering, pluraliteit ${ }^{2}$.

\section{DIFFERENTIATIE}

We kunnen over de kerk spreken in theologische woorden: Jezusbeweging, Volk Gods, Lichaam van Christus. Maar dat is voor ons doel te hoog gegrepen. Ik kies voor een bescheiden omschrijving. Onder kerk versta ik hier de sociale gestalte van het christelijk geloof. De bescheidenheid zit vooral in de beperking: De sociale gestalte is niet de enige gestalte van geloven. Het christelijk geloof kent ook individuele gestalten, die zichtbaar worden in de toewijding en het engagement van heel veel individuele christenen, al dan niet kerkelijk betrokken en het kent ook publieke gestalten, tot uitdrukking komend in een maatschappelijke en politieke betrokkenheid op de vragen en noden van de samenleving. Ze nemen de vorm aan van acties, bewegingen en organisaties, waarbinnen christenen met lotgenoten en bondgenoten samenwerken. Maar ook ndividuele en publieke gestaltn van geloven worden vanuit die sociale gestalte, die we kerk noemen, gevoed.

Deze inzet opent onze ogen voor het proces van differentiatie als een der belangrijkste kenmerken van de moderne samenleving. Dat is het eerste kernwoord. De eenheid van het leven heeft plaats gemaakt voor een uiteenwaaiering naar sectoren en deellevens. Daarbij denk ik met name aan de uitsplitsing naar privéwereld, sociale wereld en publieke wereld. Deze drie roepen elkaar op, overlappen elkaar, kunnen niet buiten elkaar, maar in het proces van modernisering zijn ze als verschillende sectoren uit elkaar gegroeid. Thans, op het hoogtepunt van de moderniteit,nu de dooi invalt, dreigen ze als ijsschotsen uit elkaar te glijden. One samenleving kraakt in haar voegen. Er trekken diepe scheuren tussen individu en gemeenschap, tussen privé en publiek.

Dat heeft ook zijn uitwerking op zingeving en levensbeschouwing. Het van oudsher heel het leven omspannende "hemelse baldakijn" (P Berger) is gescheurd. We zien een differentiatie optreden naar mens en religie, kerk en geloof, godsdienst en samenleving. De kerk als sociale gestalte van geloof heeft haar greep op die private en publieke sector, op individuele religiositeit en op de publieke moraal, meer en meer verloren. Functieverlies van de kerk, zeggen we dan. Maar wie denkt vanuit "gestalten van geloven" ziet dat anders: Het kerkelijk perspectief is te beperkt om aan dat brede spectrum van religie, geloof en godsdienstigheid recht te doen. 


\subsection{Theologische Kanttekeningen}

Ik maak hierbij een paar theologische kanttekeningen. De Reformator Luther vermeed zoveel mogelijk het woord kerk, dat hem blijkbaar teveel deed denken aan macht en onvrijheid. Hij gebruikte liever het woord christenheid ${ }^{3}$, de gemeenschap van christenen die breder is dan het kerkelijk instituut. Dit leidt ons terug naar de kern van het evangelie, het Rijk Gods.

Aan het christen-zijn zit een individuele kant: dat je als mens geboeid bent geraakt door Jezus Christus en dat je je met alles wat in je is aan Hem mag toevertrouwen in de weg van de navolging. Jezus riep individuen, vertelt ons het evangelie: bekeert $u$ want het Rijk Gods is nabijgekomen. Hij ging met ieder individu een heel eigen relatie aan, met Nicodemus, Zacheus, Maria Magdalena, de Samaritaanse en vele anderen. Christen-zijn is allereerst iets heel individueels. De Geest werkt in de harten van mensen.

Of Jezus ook bedoeld heeft dat er na Hem een kerkelijke organisatie zou ontstaan, weten we niet. Het lijkt niet waarschijnlijk. Hij sprak over het Rijk Gods, maar daarbij behoren -lezen we in het evangelie- ook nieuwe sociale verbanden, die de kring van gezin, familie, gelijkgezinden en partijgangers overstijgen: verbanden van vriendschap, zusterschap en broederschap, kortom gestalten van saamhorigheid. Dat er een christelijke gemeenschap ontstaan is waarin voor uiteenlopende individuen plaats is, zal dus niet buiten de Geest om gegaan zijn. Christen-zijn is ook iets sociaals, een nieuw levensverband waarin mensen werkelijk vrij zijn.

Tenslotte richtte Jezus de blik naarbuiten, naar het publieke leven, een samenleving die werkelijk Rijk Gods genoemd mag worden, omdat ze niet berust op het heersen van de een over de ander, maar op onderling dienstbetoon. Hij zette in op een samenleving waar gerechtigheid zou wonen, omdat er voor de werkers van het elfde uur een zelfde beloning is weggelegd als voor de kansrijken van het eerste uur. Ieder wordt verzadigd, er blijven manden vol brood over, niemand hoeft te stelen.

Aan geloven in de lijn van de Joods-christelijke traditie zitten dus individuele, sociale en publieke kanten, die elkaar oproepen. We denken bij "gestalten van geloven" aan die bredere noemer: christenheid, Rijk Gods. Wat betekent dat?

\subsection{Over- en onderschatting van de kerk}

Door deze inzet worden we bewaard voor zowel overschatting als onderschatting van de kerk. We komen uit een wereld van overschatting, waarin de kerk heel het leven en heel de samenleving in al haar gestalten omspande. Dat leidde tot het ontwikkelen van een omvattende kerkleer en 
kerkorde, een afgrenzende ecclesiologie met een opgetuigde ambtstheologie. De kerk werd te belangrijk. Het ambt schoof in een bemiddelende positie tussen God en de mens in, waardoor het volk, voortaan leken genoemd, steeds meer van de kerk afhankelijk werd. De kerk nam een overheersende positie in, zowel in het individuele als het publieke leven.

Vandaag lijkt eerder sprake te zijn van onderschatting van de kerk. De privéwereld van het individu en de publieke sector hebben zich in hoge mate verzelfstandigd ten opzichte van de kerk als instituut. We hebben te maken met mondige autonome mensen in een anonieme autonome samenleving. Deze ontwikkeling wordt meestal positief gewaardeerd, in termen van emancipatie en bevrijding. In veel opzichten terecht, maar dit doet niets af aan de blijvende betekenis van de sociale gestalte van geloven die we kerk noemen. Waar sociale verbanden wegvallen worden individuen ook steeds meer op zichzelf teruggeworpen en wordt de samenleving anoniem. Sociale verbanden, aldus de filosoof Habermas, vormen een beschermende buffer tegen de kolonisering van de leefwereld door het systeem ${ }^{4}$. Sociale verbanden zijn, aldus de theoloog Van Gennep, intermediaire structuren die bemiddelen tussen individu en samenlevings. Daar merk je ontsporingen het eerst op, bijvoorbeeld als die samenleving onvoldoende de noden van het individu in het oog heeft. Juist in haar sociale verbanden wordt de tweedeling zichtbaar in de samenleving, tussen kansrijken en kansarmen, "haves and have-nots".

Sociale verbanden hebben het in onze samenleving moeilijk. Dat geldt ook van de kerk. Naar de publieke kant heeft ze te maken met het proces van secularisering, naar de individuele kant met het proces van individualisering. Dat zijn de twee volgende trefwoorden die uit dat proces van differentiatie weglopen. Ze drukken uit dat zowel het individu als de samenleving een autonome ontwikkeling doormaken, los van kerk en geloof.

\subsection{Schaduwkanten}

Aan deze ontwikkeling zitten wel degelijk ook schaduwkanten. Door die emancipatie van het individu en van het publieke domein raakte de kerk in zichzelf gekeerd, ze ging in het defensief. Achter ons ligt een eeuw die gekenmerkt wordt door verkerkelijking, verzuiling en verburgerlijking van het christendom. De goede strijd sloeg naarbinnen en ontaardde in interne, confessionele leergeschillen. Kerkelijke organisaties ontwikkelden een eigen leven en een eigen taal, eigen regels en gewoonten en trokken scheidslijnen tussen binnen- en buitenkerkelijken. Vervolgens ontwikkelden ze missionaire strategieën om wie eerst buitengesloten waren weer binnen 
te halen. Het laatste tevergeefs. Grote groepen mensen maakten dit niet mee. De arbeiders hebben de kerk verlaten zegt men, maar terecht draaide iemand dit om: De kerk heeft de arbeiders verlaten. Ook andere groepen kwamen in de kou te staan. Na de arbeiders vertrokken de intellectuelen, toen de jeugd en thans feministisch georiënteerde vrouwen.

De kerk kon het meervoud, de differentiatie in de samenleving niet aan. Ze verstarde en raakte in zichzelf gekeerd. Ook naar de publieke kant verloor ze haar invloed. Godsdienst en levensbeschouwing worden thans gerekend tot de privéwereld, het behoren tot een kerkgenootschap heeft geen publieke betekenis meer en is in Nederland uit het bevolkingsregister verwijderd. Apostolaat en diakonaat kwijnden weg. Het kerkelijk spreken in politieke en maatschappelijke vraagstukken verstomde. Dit alles geeft aan die beide andere kernwoorden secularisatie en individualisering iets dubbels. Ze staan enerzijds voor autonomie, anderzijds voor relevantieverlies. Over beide iets meer.

\section{SECULARISERING}

Het woord secularisatie heeft vooral een negatieve klank gekregen. Het wordt vereenzelvigd met neergang en achteruitgang van het kerkelijk leven, vooral in de steden. Dat is een te beperkte visie. Veel van wat ik schetste zie je dan niet. Secularisatie ziet volgens Gerard Dekker ${ }^{6}$ op drieërlei ontwikkeling: vermindering van godsdienstigheid (1), beperking van de reikwijdte van de godsdienst (2), aanpassing van de godsdienst aan ontwikkelingen in de samenleving (3). Op alle drie aspecten richt zich thans de kritiek.

(1) Sommigen twijfelen aan die vermindering van godsdienstigheid. Geloofscrisis is gezichtsbedrog, luidt de uitdagende stelling van Dick Tieleman ${ }^{7}$. Het is inderdaad een opvallend verschijnsel dat, terwijl de kerk aan invloed verliest, nieuwe vormen van religiositeit en spiritualiteit om ons heen opbloeien. Blijkens de laatste versie van het onderzoek "God in Nederland" beschouwt tweederde van alle Nederlanders zichzelf als gelovig, terwijl tegelijk meer dan $60 \%$ zich niet meer tot een kerkgenootschap rekent ${ }^{8}$. Op deze kloof tussen geloof en kerk wijst ook een Duits onderzoek van V Drehsen onder de titel: "Wie religionsfähig ist die Volkskirche?"9. De kerk is haar "Fähigkeit” voor religie kwijtgeraakt. Wij zijn zo bevangen door rationaliteit dat we het zintuig hiervoor verloren hebben. Al decennia geleden sprak de godsdienstpsycholoog Han Fortmann over een waarnemingsprobleem in onze Westerse cultuur ${ }^{10}$. We zijn de ontvankelijkheid, de overgave, kwijtgeraakt. We missen de verwondering om 
ons door de geschapen werkelijkheid te laten aanspreken. De godsdienstsocioloog Meerten ter Borg zit op ditzelfde spoor. Veel mensen geloven niet in God, maar deze goddeloosheid betekent nog geen ongeloof, meent hij". De seculariseringsthese noemt hij een vergissing, want het gaat slechts om de teloorgang van een bepaalde historische vorm van religie.

(2) Het tweede punt, de beperking van de reikwijdte, vraagt historisch onderzoek. Dekker neemt als ijkpunt voor het secularisatieproces in de Gereformeerde Kerken het jaar 195012. Maar was het kerkelijk leven toen zo ideaal? Velen verlangen niet terug naar de kerk van hun jeugd. Peter van Rooden rekent in zijn boek "Religieuze regimes"13 op historische gronden af met de secularisatietheorie, die naar hij meent veel te grofmazig is als men haar wil toepassen op de ontwikkeling van het kerkelijk leven in Nederland vanaf de Reformatie. Al naar de politieke en maatschappelijke situatie heeft de verhouding tussen godsdienst, politiek en maatschappij in verschillende tijdperken andere vormen aangenomen. Van secularisatie is echter geen sprake. Dat de these niet opgaat heeft een prettige bijkomstigheid: De toekomst van godsdienst in Nederland is open. De kerkhistoricus Augustijn ${ }^{14}$ toont aan dat de oplopende ontkerkelijkingscijfers, van ruim $2 \%$ aan het begin van deze eeuw tot bijna $60 \%$ nu, op zich weinig zeggen. Men moet cijfers in hun context verstaan. Zoals het in het verleden normaal was om bij een kerk te horen, zo is het thans normaal dat men niet tot een kerk behoort. Normaal, dat wil zeggen overeenkomstig de heersende norm, de macht der gewoonte. Hij waarschuwt voor een geromantiseerd beeld van het kerkelijk verleden.

Wat tenslotte de aanpassing van de godsdienst betreft, dient onderscheid gemaakt te worden tussen aanpassing als assimilatie en als accommodatie. In het eerste geval is sprake van versmelting, waarbij de christelijke traditie haar eigen identiteit verliest. In het tweede geval is sprake van een gezonde aanpassing: "de Joden een Jood, de Grieken een Griek". Het christendom heeft zich de eeuwen door aan steeds nieuwe omstandigheden aangepast. In een tijd van ontkerstening van Europa kunnen we daarom veel leren van het voorafgaande proces van kerstening, aldus Anton Wessels: "Waarom zouden ook niet de Romeinse, Keltische en Germaanse schatten in het nieuwe Jeruzalem worden ingebracht?" 15

De secularisatiethese wordt dus terecht gekritiseerd, maar dit neemt de zorg niet weg. Auteurs als Ter Borg gaan uit van een functioneel religiebegrijp, waar bijvoorbeeld ook het Ajax-strooiveld op Westgaarde, waar de as van overleden voetbalsupporters wordt verspreid, onder valt: Allemaal religie. Je hoeft nog geen Barthiaan te zijn om toch kritische kanttekeningen te plaatsen bij alle optimisme over moderne religiositeit en 
Celestijnse spiritualiteit. Uitgaande van een substantieel religiebegrip baart het traditieverlies van "die bepaalde historische vorm van religie" die Christendom heet veel anderen, ik meen terecht, wel zorgen. Het theologisch onderscheid tussen religieus besef en christelijk geloof hangt hiermee samen dat het geloof de religie onder kritiek plaatst. Zo mogen we kritisch staan tegenover vormen van zelfverlossing die aan de genade in Christus voorbijgaan en vormen van godsdienst die onverschillig staan ten opzichte van racisme en maatschappelijk onrecht.

\section{INDIVIDUALISERING}

Zoals er in het publieke domein sprake is van secularisering, is er in het privédomein sprake van individualisering ${ }^{16}$, het derde trefwoord. De kerk is zo weinig gemeenschap, hoort men dan. De kerkelijke gemeente hangt als los zand aan elkaar. Mensen individualiseren en gaan hun eigen weg. Wie zich niet kan redden wordt aan haar of zijn lot overgelaten. Zo wordt de achteruitgang van de kerk verbonden met het individualiseringsproces. Met een variatie op Paulus: Ieder lette slechts op zijn eigen belang en niet op dat van anderen. Het nuttigheidsdenken vraagt gulzig: Wat heb ik eraan en wat koop ik ervoor?

Ook hier lijkt me enige nuancering op z'n plaats. Van individualisering valt namelijk veel goeds te zeggen. De autonomie die het resultaat is van de cultuur van de Verlichting is geen vijand van de christelijke traditie. Terecht wijst men erop dat hierin niet alleen de lijnen van Renaissance en Humanisme worden doorgetrokken, maar ook die van Reformatie en Pitisme ${ }^{17}$. De existentiële vraag van Luther, "Hoe krijg ik een genadig God?", is hiervan een exponent. Uit het collectief besef van de Middeleeuwen wordt het individu geboren. Het onderricht van de kerk is erop gericht mensen mondig te maken, op eigen benen te doen staan en op hun eigen geweten te doen vertrouwen. Individualiserende mensen worden minder afhankelijk en leren voor zichzelf op te komen. Tegelijk is individualiseren ook een vorm van overleven. Dat laatste geldt met name voor jongeren ${ }^{18}$. Tegenover de chaos van de buitenwereld, een leven in veelvoud, zoeken ze de beschutting van een veilige en overzichtelijke binnenwereld, om zichzelf te hervinden. Anders houd geen mens het moderne leven vol.

Het gevolg is dat kerkelijke betrokkenheid ingrijpend verandert. Velen gaan selectief om met het aanbod van de kerk. Ze komen er wanneer ze er behoefte aan hebben, dat wil zeggen incidenteel en bij gelegenheid. Zulke gelegenheid-zoekers zijn niet minder betrokken, maar wel anders. 
Ze zijn lid van de kerk, zoals ze lid zijn van de Wegenwacht: Bij pech onderweg zoeken ze een praatpaal. Als ze meedoen zijn ze vaak hevig geinteresseerd, vooral als het over henzelf gaat. De tijd van de Grote Verhalen is voorbij. Steeds minder hebben mensen een gedeelde ideologie. Maar als het gaat om de individuele biografie, de betrokkenheid bij een doopviering, de inzegening van een relatie of het deelnemen aan een uitvaart, loopt de temperatuur op en wordt iets ervaren van een hoog gemeenschapsgehalte ${ }^{19}$. Mag de dienst der kerk ook niet het karakter van service hebben?

Maar er is ook een andere kant. Individualisering als "ieder voor zich" kan ten koste gaan van solidariteit. De kerk is dikwijls de spiegel geweest van de samenleving. Het zou jammer zijn als een liberale samenleving waarin het marktdenken alles overheerst, weerspiegeld wordt in een liberale vrijblijvende kerk. Een kerkelijke gemeenschap zal toch ook iets moeten hebben van een kritische tegencultuur. Een gemeenschap waarin mensen zich gekend en herkend weten, is een weldaad. Een gemeente als sociaal vangnet blijft nodig, voor al die mensen die niet mobiel en zelfredzaam zijn. Een kerk die geen bondgenoot is van de zwakken in de samenleving en niet langer de stem versterkt van wie geen stem hebben, houdt op kerk te zijn. Solidariteit, van huis uit een strijdwoord, heeft zijn angel verloren en is synoniem geworden voor vrijblijvende medemenselijkheid $^{20}$. Zo wordt het armoedevraagstuk opnieuw tot een testcase. In de steden weet men dit. De kerk wordt er dagelijks mee geconfronteerd.

\section{PLURALITEIT}

Geloven in meervoud is een passend antwoord zoeken op een leven in meervoud, om aan differentiatie, secularisering en individualisering het hoofd te bieden. Dit vraagt een rechtdoen aan pluraliteit in de vorm van de verschillende gestalten van geloven. Hier liggen kansen en uitdagingen, juist in de stad van de mens en wel naar twee kanten. De eerste opgave is aansluiting zoeken bij de religieuze ervaring van het individu, bij wat mensen echt beweegt, in hun angsten en hun kwetsbaarheid, hun verlangen en hun falen, hun nood en hun lijden. Het evangelie schept ruimte, zegt mensen dat ze door God aanvaard zijn en doet hen opademen omdat de druk van de wet wegvalt. Dat is goed nieuws, ook voor moderne geindividualiseerde mensen. De tweede opgave ligt in het publieke domein, het geloven in het openbaar, het onderkennen van maatschappelijke vraagstukken en daarop inspelen. De kerk mag zich in deze richting profileren. Temidden van de vele kleine verhalen mag ook haar verhaal er 
zijn. De verontschuldigingscultuur voorbij, mag ze minder anoniem en met meer vrijmoedigheid aan de weg timmeren dan we dat de laatste decennia gewend waren. Deze presentie van de kerk zal vooral het werk zijn van individuele christenen, ieder op haar en zijn plaats in de samenleving. Over beide opgaven iets meer.

De antropologische wending naar het individu gaat de traditionele kerken nog steeds niet gemakkelijk af. Er is, zo zagen we, sprake van een groeiende kloof tussen geloof en kerk. Waarom profiteert de kerk zo weinig van de renaissance van de religieuze vraag? Al decennia geleden constateerde de Duitse praktisch-theoloog Ernst Lange een gebrek aan religieuze socialisatie en indigenisatie binnen de volkskerk. Hij sprak van een Bildungs dilemma, omdat de vorming tot mondigheid en zelfstandig geloven tevens leidde tot een geringere betrokkenheid en grotere distantie ten opzichte van de traditionele kerk ${ }^{21}$. Hoe mondiger mensen worden, des te minder ze de kerk blijkbaar nodig hebben. Uit vrees hiervoor heeft de kerk vaak geprobeerd mensen onmondig te houden. Bonhoeffer heeft hier met kracht tegen geprotesteerd, in paradoxale woorden, zoals: "De mondige wereld is godlozer en daardoor misschien dichter bij God dan de onmondige wereld" 22 .

Ook Abraham Kuyper koos voor de mondigheid van de individuele gelovige. In tegenstelling tot de onzichtbare kerk, die berust op Gods verkiezing, is de zichtbare kerk naar zijn mening een vrucht van toetreding op grond van vrije keuze van het belijdend individu. Deze kerk is geen doel in zichzelf, maar een brug naar de samenleving. Zijn onderscheid tussen "kerk als instituut" en "kerk als organisme" geeft alle ruimte aan individuele gelovigen om hun roeping te vervullen op alle terreinen des levens. Dat noemt hij kerk als organisme. Daarbij vergeleken heeft het instituut een bescheiden plaats. Het is vooral van vormende waarde ${ }^{23}$.

Lange en in zijn voetspoor Drehsen ${ }^{24}$ wijzen erop dat in een plurale situatie de zondagse eredienst steeds minder een samenbindende factor kan zijn. Zij zien die eerder in de casualiën, de gelegenheidsdiensten bij doop, huwelijk en overlijden, waarin een directe relatie gelegd kan worden met de individuele beleving van de deelnemers. Het gaat niet aan hier geringschattend te spreken over "geloven op wieltjes". Religie op zulke scharniermomenten in het leven is van existentiële betekenis. De Duitse taal kent hiervoor de uitdrukking "Kontingenzbewältigung". Wanneer de kerk in liturgie en pastoraat present is in de ultieme vragen van leven en dood, lijden en lot, angst en schuld, blijft voor haar een belangrijke functie weggelegd. Dit vraagt een nauw op elkaar betrekken van theologie en biografie zoals deze plaats vindt in eigentijdse vormen van hermeneutisch pastoraat 25 . 
Deze ontwikkeling leidt tot een differentiatie in lidmaatschap en kerkelijke betrokkenheid, die de kerk voor tweeërlei opgave plaatst: enerzijds aansluiting zoeken bij de religieuze ervaring van het individu en anderzijds trouw blijven aan de identiteit van de christelijke geloofstraditie. Een recente katholieke studie over de relatie van kerk en moderniteit vangt beide onder én titel: "Kirche als Wahlheimat" ${ }^{26}$. De schrijver, A Wollbold, introduceert hiermee een spanningsvol begrip, dat met het moderne leven gegeven is. "Heimat" staat voor geborgenheid, een vertrouwde wereld waarop men altijd kan terugvallen. "Wahl" staat voor keuzevrijheid. Mensen zijn op zoek, maar dan in twee richtingen. Enerzijds zoekt men vrijheid en autonomie, anderzijds een ruimte waarin men geborgenheid vindt. De kerk die hij voor zich ziet is een gemeenschap van weggenoten, waarin uiteenlopende vormen van participatie mogelijk zijn, zonder meteen onderscheid te maken tussen binnen- en buitenkerkelijken.

Deze spanning kent de Gereformeerde (Hervormde) Kerk in Nederland al vanaf haar ontstaan. In de eerste eeuw na de Reformatie telde deze kerk niet alleen "lidmaten", maar daarnaast ook een grote schare "liefhebbers" van de gereformeerde religie ${ }^{27}$. De eersten behoorden tot de avondmaalsgemeenschap en vielen onder de kerkelijke tucht. Deze gemeenschap was geen volkskerk maar eerder te vergelijken met een kloostergemeenschap. De tweede groep overtrof in aantal verre de eerste, maar nam een meer gedistantieerde positie in. $\mathrm{Zij}$ hoorden het Woord en makkten gebruik van de diensten van de kerk, maar zonder zelf als lidmaat toe te treden. In onze tijd gebruikt men hiervoor termen als partiële identificatie en selectieve participatie. Dat klinkt beter dan het discriminerende onderscheid tussen "kern" en "rand". Een aantal mensen voelt zich betrokken bij de kerk, maar kan zich om uiteenlopende redenen maar ten dele met de geloofsgemeenschap identificeren. Of men doet selectief mee in bepaalde projecten, een leerhuis of een inloophuis. De belangrijke vraag is dan of het ook in onze tijd lukt om rond de slinkende geloofsgemeenschap opnieuw een brede kring te verzamelen van belangstellenden, vrienden, donateurs en mensen die bij bepaalde gelegenheden gebruik maken van het pastorale aanbod van de kerk. De exclusiviteit van een geloofsgemeenschap en de inclusiviteit van een gerichtheid op alle mensen vormen geen tegenstelling. In een missionaire gemeente roepen ze elkaar op en versterken ze elkaar. Modellen van gemeenteopbouw dienen aan deze dubbelstrategie getoetst te worden.

De gereformeerde kerken hebben altijd grote waarde gehecht aan de zelfstandigheid van de plaatselijke kerk in samenhang met het territoriale model. Dit betekent dat het dorp of de straat waar men woont bepalend is 
voor de vraag van welke kerkgemeenschap men lid is. Het is in toenemende mate een vraag of hiermee recht gedaan kan worden aan een groeiende pluraliteit binnen een geloofsgemeenschap. Deze pluraliteit heeft ertoe geleid dat met name in de steden modaliteits- en mentaliteitsgemeenten zijn ontstaan die zich op een bepaalde wijze profileren. $\mathrm{Zij}$ trekken daardoor belangstellenden uit een veel bredere kring dan de eigen wijkgemeente. Zo 'n gemeente trekt op haar beurt weer een predikant aan die in het eigen profiel van deze gemeente past. Zo ontstaan gemeenten die een confessionele kleur, dan wel een evangelische of charismatische kleur, dan wel een hoog-liturgische of een meer liberale kleur vertonen, of zich presenteren als een politiek-kritische basisgemeente. Dit komt tot uitdrukking in de liturgie, zoals in de keuze van de liederen en het karakter van de prediking, en in de verplichtingen die het lidmaatschap van een bepaalde gemeente met zich meebrengt, de wijze waarop al of niet vorm gegeven wordt aan het priesterschap van alle gelovigen. Kerk als "Wahlheimat" betekent ook dat iemand zich in de ene gemeente wel thuis voelt en in de andere niet. Men zal zijn keuze dus maken voor een gemeente van de eigen richting. Ik ben geneigd deze in de praktijk gegroeide keuzevrijheid positief te waarderen, mits gemeenten van verschillende kleur op classikaal niveau met elkaar in gesprek blijven, elkaar corrigerend en kritiserend.

De keuze voor een open kerk komt ook tot uitdrukking in vormen van presentie binnen het publieke domein. Ik citeer nogmaals Bonhoeffer: "De kerk moet meewerken aan de wereldlijke taken van het gemeenschapsleven, niet heersend maar helpend en dienend. $\mathrm{Zij}$ moet de mensen van alle beroepen voorhouden wat een leven met Christus is, wat het inhoudt 'te zijn voor anderen'". Of, nog korter geformuleerd: “Ons christen zijn zal in deze tijd bestaan uit slechts twee elementen: bidden en onder de mensen het goede doen" 28. Dit leidt tot het model "kerk voor anderen".

Dit kan tot uitdrukking komen in een deelname aan het publieke debat over waarden en normen, medisch-ethische vraagstukken, de inrichting van een rechtvaardige samenleving, de opvang van asielzoekers, de bestrijding van het armoedevraagstuk. In Nederland zijn dit belangrijke thema's. Zuid Afrika heeft haar eigen thema's, die o.a. indrukwekkend naar voren komen in het debat over "Waarheid en verzoening" in relatie tot racisme en apartheid. Daarnaast zijn er vormen van christelijke en kerkelijke presentie ontwikkeld om met woord en daad aanwezig te zijn in de wereld van de kansarmen via "urban mission" en diakonale projecten als het drugspastoraat en de "inloophuizen" in de $\operatorname{steden}^{29}$. De gerichtheid op het individu mag dus nooit ten koste gaan van de aandacht voor de noden van de samenleving. 
Geloven in "de stad van de mens" blijkt ruim dertig jaar na het verschijnen van het geruchtmakende boek van Harvey Cox nog altijd een belangrijk vraagstuk te zijn voor de kerk. Ze is er nog maar ten dele in geslaagd antwoorden te vinden op de zich ontwikkelende moderniteit. Een positieve waardering van de pluraliteit, zoals deze tot uitdrukking komt in verschillende gestalten van geloven, biedt naar mijn mening aanknopingspunten voor een positief-kritische benadering van het moderniseringsproces. Een kerk die bereid is haar machtsaanspraken op mens en samenleving op te geven om in een dienende gestalte kerk van Jezus Christus te kunnen zijn, verliest wel aan invloed maar wint aan geloofwaardigheid. Hier worden de omtrekken zichtbaar van een ecclesiologisch ontwerp dat de moderniteit serieus neemt, maar tevens trouw blijft aan de identiteit van de kerk der eeuwen. Hieraan een bijdrage leveren zie ik in onze tijd als een van de belangrijkste opgaven voor de praktische theologie.

Alle praktische theologie is contextueel. De Nederlandse context, van waaruit dit artikel geschreven is, verschilt aanmerkelijk van die van Zuid Afrika. In hoeverre kan hier sprake zijn van herkenning? Het is mijn hoop dat dit artikel niet alleen informatieve waarde heeft, maar ook kan bijdragen tot een gedeeld probleembewustzijn, waarin wij vanuit verschillende contexten in alle wederkerigheid elkaar van dienst kunnen zijn en groeien in gemeenschappelijk theologiseren.

\section{NOTEN:}

1 H Cox, De stad van de mens. Het levenspatroon van de moderne wereld in theologisch perspectief, Utrecht 1966.

2 Vergelijk voor deze begrippen: G Heitink, Praktische theologie: geschiedenis, theorie, handelingsvelden, Kampen 1993, 39-43, 45-49.

3 Vergelijk $\mathrm{O} \mathrm{J}$ de Jong, "De kerk in haar eigen lied", in: J Hallebeek en B Wirix (red), Met het oog op morgen, Zoetermeer 1996, 82.

4 Zie over Habermas: H de Roest, Communicative Identity. Habermas' perspectives of discourse as a support for practical theology, Kampen 1998.

5 F O van Gennep, De terugkeer van de verloren Vader, Baam 1989, $246 \mathrm{ev}$.

6 G Dekker, "Secularisatie in de westerse samenleving", in: G Dekker en K U Gäbler (red), Secularisatie in theologisch perspectief, Kampen z.j., 32.

7 D Tieleman, Geloofscrisis als gezichtsbedrog. Spiritualiteit en pastoraat in een postmoderne cultuur, Kampen 1995.

8 G Dekker, J de Hart en J Peters, God in Nederland 1966-1996, Amsterdam 1997.

9 V Drehsen, Wie religionsfahig ist die Volkskirche? Sozialisationstheoretische Erkundungen neuzeitlicher Christentumspraxis, Gütersloh 1994.

10 H M M Fortmann, Als ziende de onzienlijke, Hilversum 21974, 1295 ev.

11 M B ter Borg, Het geloof der goddelozen, Baarn 1996. 
12 G Dekker, De stille revolutie, De ontwikkeling van de Gereformeerde Kerken in Nederland tussen 1950 en 1990, Kampen 1992.

13 P van Rooden, Religieuze regimes. Over godsdienst en maatschappij in Nederland, 1570-1990, Amsterdam 1996.

14 C Augustijn, De macht der gewoonte. Het ontkerkelijkingsproces in Nederland, in: H Stoffels (red), Onverwachte gasten, Kampen 1996, 95-103.

15 A Wessels, Kerstening en ontkerstening van Europa. Wisselwerking tussen evangelie en cultuur, Baarn 1994, 220.

16 Zie over individualisering met name: $\mathrm{F}$ de Lange, leder voor zich? Individualisering, ethiek en christelijk geloof, Kampen 1993.

17 Vergelijk bijv D Rössler, Grundriss der Praktischen Theologie, Berlin 1986, 78.

18 Vergelijk H A Alma, Geloven in de leefwereld van jongeren, Kampen 1993, 232.

19 Zie over individualisering en religie met name: $\mathrm{V}$ Drehsen, $a w, 1994 ; \mathrm{H}$ Luther, Religion und Alltag. Bausteine zu einer Praktischen Theologie des Subjekts, Stuttgart 1992.

20 Zie bijv. P M Zulehner, H Denz, A Pelinka en E Tàlos, Solidarităt. Option für die Modernisierungsverlierer, Wien 1996.

21 Zie met name: E Lange, Bildung als Problem und Funktion der Kirche, in: E Lange, Sprachschule für die Freiheit, München 1989, 159-200.

22 D Bonhoeffer, Verzet en overgave, (nieuwe editie), Baarn 1972, 302.

23 Zie: C Augustijn en J Vree, Abraham Kuyper: vast en veranderlijk. De ontwikkeling van zijn denken, Zoetermeer 1998.

24 Drehsen, $a w, 174$ ev. Hij noemt dit “Die Heiligung von Lebensgeschichten".

25 G Heitink, Pastorale zorg: theologie, differentiatie, praktijk, Kampen 1998, 6985, $151-208$.

26 A Wollbold, Kirche als Wahlheimat. Beitrag zu einer Antwort auf die Zeichen der Zeit, Freiburg 1998.

27 Vergelijk A Th van Deursen, Mensen van klein vermogen. Het "kopergeld" van de Gouden Eeuw, Amsterdam 1992, 298 ev.

28 Bonhoeffer, $a w, 251,317$.

29 Ik verwijs naar: K A Schippers e a, Kerkelijke presentie in een oude stadswijk, Kampen 1990; S Stoppels, Gastvrijheid. Het inloophuis als vorm van kerkelijke presentie, Kampen 1996. 